\title{
Cultivation and Breeding of Chinese Medicinal Plants in Germany
}

Authors

Affiliations
Heidi Heuberger ${ }^{1}$, Rudolf Bauer ${ }^{2}$, Fritz Friedl ${ }^{3}$, Günther Heubl ${ }^{4}$, Josef Hummelsberger ${ }^{5}$, Rainer Nögel ${ }^{5}$, Rebecca Seidenberger ${ }^{1}$, Paula Torres-Londoño ${ }^{6}$

The affiliations are listed at the end of the article

\author{
Key words \\ - plant breeding and selection \\ - Chinese herbal medicine \\ - agriculture \\ - taxonomy \\ - pharmaceutical quality \\ - reproduction biology \\ - seed multiplication
}

\section{Abstract \\ $\nabla$}

Chinese herbal medicine (CHM) is increasingly used in Germany and Europe. Due to the need for herbal drugs of consistent quality and reliable supply, methods for commercial field cultivation and post-harvest processing under south German conditions have been developed for selected plant species used in CHM since 1999. The project used an interdisciplinary approach covering all aspects from seed sourcing to medicinal application. This paper describes the outcome of the agricultural seed and field experiments, breeding program, botanical and chemical characterization of the experimental material, comparison of experimental and imported herbal material with respect to their pharmaceutical quality, transfer of production methods and plant material to specialized farmers, medicinal application and, finally, infor- mation for users along the chain of distribution about the benefits of the locally produced herbal material.

\section{Abbreviations \\ $\checkmark$ \\ BLBP: $\quad$ "Bayerische Landesanstalt für Bodenkultur und Pflanzenbau", the precursor to the LfL \\ CHM: $\quad$ Chinese herbal medicine \\ DECA: Association for the Documentation of Chinese Herbal Therapy \\ LfL: Bavarian State Research Center for Agriculture \\ PEG: polyethylene glycol \\ SMS: International Society for Chinese Medicine}

\section{received May 4, 2010 \\ revised October 6, 2010 \\ accepted October 18, 2010}

\section{Bibliography}

DOI http://dx.doi.org/

10.1055/s-0030-1250528

Published online November 12 , 2010

Planta Med 2010; 76: 1956-1962 @ Georg Thieme Verlag KG Stuttgart . New York . ISSN 0032-0943

Correspondence

Dr. Heidi Heuberger

Bavarian State Research

Center for Agriculture

Institute of Crop Science and Plant Breeding

Medicinal and Aromatic Plants

Vöttinger Str. 38

85354 Freising

Germany

Phone: + 498161713805

Fax: + 498161715225

Heidi.Heuberger@LfL.bayern.de

\section{Introduction}

\section{$\nabla$}

Medicinal plants play a key role in Chinese medicine [1-3]. In present-day Germany and Europe, Chinese herbal treatment is practiced by a specially-qualified group of physicians and naturopaths. Herbal retailers import the herbs from Asia and distribute these to specialized pharmacies where the herbs are mixed according to prescriptions, and decoctions are prepared. The import of raw, dried plant products of Asian species which are mostly unknown in Europe poses problems ranging from drug material quality to sustainability of supply. Thus, great efforts have to be made to analyze the quality and purity of these imports, especially in view of reports of dangerous adulterations and contaminations $[1,4,5]$. Therefore, homogenous herbal materials of well-documented origin and reliable identity are required which are free of adulterations and certified according to recognized quality standards. Field cultivation under controlled and documented conditions is a step towards improving drug safety and pharmaceutical quality characterized by its identity, purity, and active ingredients.

The topic of this paper is the development of sustainable field production methods including plant improvement by breeding and the subsequent transfer to farmers' practice as it has been realized in an interdisciplinary research project at the Bavarian State Research Center for Agriculture since 1999.

\section{Materials and Methods}

$\nabla$

\section{Selected plant species}

The plant species for which production methods were to be developed were selected based on the following criteria: the climatic needs of the plants, supply difficulties, the advantage of local production (for example controlled quality), the 
Table 1 Investigated plant species and state of development.

\begin{tabular}{|c|c|c|c|}
\hline Roots and rhizomes used & Plant part used & Chinese drug name & State of development \\
\hline $\begin{array}{l}\text { Angelica dahurica (Fisch.) Benth. \& Hook. f. ex Franch. } \\
\text { \& Sav., Apiaceae }\end{array}$ & Radix & Baizhi & commercial cultivation \\
\hline Angelica sinensis (Oliv.) Diels & Radix & Danggui & not suitable for German lowlands \\
\hline Artemisia scoparia Waldst. et Kit., Asteraceae & Herba & Yinchenhao & commercial cultivation, breeding in progress \\
\hline $\begin{array}{l}\text { Astragalus mongholicus var. mongholicus (sub } \\
\text { A. membranaceus [Fisch.] var. mongholicus [Bunge] } \\
\text { P. K. Hsiao), Fabaceae }\end{array}$ & Radix & Huangqi & commercial cultivation, breeding in progress \\
\hline $\begin{array}{l}\text { Bupleurum chinense DC., B. scorzonerifolium Willd., } \\
\text { Apiaceae }\end{array}$ & Radix & Chaihu & yield too low, breeding in progress \\
\hline Coix lacryma-jobi var. mayuen (Roman.) Stapf, Poaceae & Semen & Yiyiren & research started \\
\hline Glycyrrhiza uralensis Fisch. Ex DC, G. glabra L., Fabaceae & Radix et Rhizoma & Gancao & research started \\
\hline Leonurus japonicus Houtt., Lamiaceae & Herba & Yimucao & commercial cultivation, breeding in progress \\
\hline Ligusticum chuanxiong Hort., Apiaceae & Rhizoma & Chuanxiong & not suitable for German lowlands, plant propagation \\
\hline Paeonia lactiflora Pallas, Paeoniaceae & Radix & Chishao & suitable cultivars identified, research in progress \\
\hline Prunella vulgaris L., Lamiaceae & Spica & Xiakucao & production method for short shoots available \\
\hline Salvia miltiorrhiza Bunge, Lamiaceae & Radix et Rhizoma & Danshen & commercial cultivation, breeding in progress \\
\hline Saposhnikovia divaricata (Turcz.) Schischk., Apiaceae & Radix & Fangfeng & commercial cultivation, breeding in progress \\
\hline Scrophularia ningpoensis Hemsl., Scrophulariaceae & Radix & Xuanshen & no plant material available \\
\hline Scutellaria baicalensis Georgi, Lamiaceae & Radix & Huangqin & commercial cultivation \\
\hline Sigesbeckia pubescens (Makino) Makino, Asteraceae & Herba & Xixiancao & commercial cultivation \\
\hline Tribulus terrestris L., Zygophyllaceae & Fructus & Baijili & not suitable due to low yield, no method for fruit separation \\
\hline Xanthium sibiricum Patrin ex Widd., Asteraceae & Fructus & Cang'erzi & commercial cultivation \\
\hline
\end{tabular}

large quantities needed, the high price, and finally that the plant should be neither a shrub nor an aquatic plant. In total, 19 species commonly used in CHM were investigated (see $\bullet$ Table 1 ).

The challenges of introducing a whole group of new plant species for CHM into agricultural practice exceeded the usual subjects for agricultural research. These challenges included the lack of literature on cultivation practices, difficult sourcing and frequently poor quality of seeds, uncertain botanical identity, the reservations expressed by users concerning the relevance of pharmaceutical quality and the medicinal effectiveness when not produced in Asia.

\section{Approach and project partners}

Therefore a comprehensive approach had to be chosen and competent partners for interdisciplinary cooperation were found. Taxonomic identification and botanical characterization of the seed accessions was carried out by G. Heubl using morphological and histological parameters, DNA sequencing, and genetic fingerprint analysis. R. Bauer analyzed the dried plant material from the field experiments for active ingredients in accordance with the Chinese pharmacopoeia $[6,7]$ and compared their chemical patterns to original Chinese samples applying chromatographic methods. U. Bomme, Institute of Plant Breeding and Crop Science, Bavarian State Research Center for Agriculture, LfL, Freising, Germany, was responsible for the entire project management. He carried out field experiments in close cooperation with the experimental stations of LfL to test different accessions and develop sustainable cultivation methods, seed multiplication including physiological and germination enhancement, as well as adaptation to local conditions. The breeding program for six species (see Table 1) was established by H. Heuberger in 2004 and has been continued by R. Seidenberger. It was supported by the LfLworking groups in tissue culture, genetic analysis, and seed testing. Selected samples of imported and experimental herbs were analyzed for pharmaceutical quality (identity, purity and active ingredients) as well as sensory quality by experts at the laboratories of the two companies PhytoLab and Kräuter Mix. The exper- imental and, subsequently, also locally-grown commercial herbs were observed in the medicinal application coordinated by $\mathrm{F}$. Friedl, Association for the Documentation of Chinese herbal Therapy, DECA, and by J. Hummelsberger, International Society for Chinese Medicine, SMS. Finally, the production methods which were developed and suitable seed accessions were transferred to experienced farmers starting with commercial cultivation comissioned by two herbal wholesalers in 2005.

\section{Results and Discussion \\ $\nabla$}

\section{Botanical identification}

Most seed sources were correctly labelled. However, the botanical characterization of all seed accessions proved to be important because in some cases seeds were mislabelled. One Angelica dahurica accession was revealed as A. archangelica L. and some Astragalus mongholicus accessions were A. luteolus H.T. Tsai \& T.T. Yu which is not specified in the Chinese pharmacopoeia $[6,7]$. On the other hand, several accessions of Leonurus heterophyllus and $L$. sibiricus were identified as L. japonicus, the official species, others as the nonofficial L. quinquelobatus Gilib. or L. panzerioides M. Pop. All accessions that were purchased as Rheum tanguticum were either identified as $R$. palmatum and $R$. officinale, both official, or as another species that could not be utilized. Finally, the single accession of Scrophularia ningpoensis showed to be S. nodosa L.

Molecular analyses using DNA-sequencing and DNA-fingerprinting techniques that accompanied botanical identification in most cases ensured taxonomic identity.

\section{Patterns and levels of active ingredients}

The patterns of active ingredients of imported Chinese herbal material analyzed by TLC and HPLC were almost identical with most experimental plant materials. Exceptions were mostly materials from species which were not compliant with the pharmacopoeia (for example Angelica archangelica, Scrophularia nodosa). 
In the chromatograms of almost all experimental Rheum palmatum and $R$. officinale accessions, a rhaponticin band developed except for some samples of one $R$. officinale accession which were free of rhaponticin as required by the Chinese pharmacopoeia [6, 7]. This showed that the tool of TLC to avoid adulterations with $R$. rhaponticum produces false positive results. Therefore, it is suggested that the qualitative method should be replaced by a quantitative assay combined with a maximum level of rhaponticin in the upcoming European monograph for Radix et Rhizoma Rhei. The levels of active ingredients contained in all experimental herbal materials met the requirements of the Chinese pharmacopoeia $[6,7]$ provided the species also complied with the pharmacopoeia. However, the level of active ingredients contained in the accessions varied widely within one species. Based on the analytical results, accessions with high levels of active ingredients were chosen to be released for commercial seed multiplication and cultivation.

The methods for TLC and assays had to be adapted in some cases. For example, the monograph of Herba Sigesbeckiae does not describe any TLC or assay, therefore a TLC system was developed to compare flavonoid patterns of different seed accessions. As another example, the assay for stachydrine as described in the monograph of Herba Leonuri japonici was not reproducible. Therefore the quantification of flavonoids according to Herba Passiflorae of the European pharmacopoeia [8] was adapted to characterize the level of active ingredients of different accessions and field treatments.

\section{Development of production methods}

The research goal was to develop sustainable methods of field cultivation suitable for commercial large-scale (several hectares) production of high-quality herbal material in accordance with good agricultural practice. The traditional "pao zhi” processing was not part of the studies. Therefore, important aspects which had to be considered were economical criteria, such as yield, possibilities for mechanization, labor intensity and plant costs, as well as produce quality, such as the level of active ingredients and purity. Table 1 lists all species under study and the respective state of development.

The first step into agronomic experimentation was the collection of seed and of information on field cultivation in other countries. Only scant information was available in English. Single publications on plant botany, seed treatment, in vitro cultivation, or product quality could be found for some species. This was the base for experimental questions and designs in combination with the experience of previous domestication projects. More comprehensive information on field cultivation methods in China was provided by Chinese agricultural institutions during a scientific visit there in 2004.

At the beginning, seed sourcing from China was not possible. Therefore, one to six accessions per species were purchased from international seed companies. Subsequently, personal contacts and the Chinese National Tree Seed Corporation became relevant sources. Due to small quantities, high prices, and/or sometimes poor quality, the seed had to be multiplied before agricultural trials could be started. Seed multiplication went along with adaptation to the local growing conditions and increasing seed vigor. Seed of several species showed poor germination despite its high vigor. Various seed treatments were tested to overcome the socalled seed dormancy, typical of many wild plant species. For example, the germination rate of Angelica dahurica could be improved by either stratification for four weeks, by incubation in an osmotic solution (polyethylene glycol, PEG 6000) for two weeks, or by alternating temperatures during seed germination (8 hours $30^{\circ} \mathrm{C}, 16$ hours $20^{\circ} \mathrm{C}$ ) [9]. Also Saposhnikovia divaricata germination can be improved by stratification, incubation in PEG (two weeks) or in water (72 hours) [9]. The seed of some accessions of Astragalus mongholicus did not absorb water unless the seed coat was mechanically or chemically damaged.

The field experiments were conducted at the two experimental stations: Baumannshof and Puch of LfL. The location Baumannshof is characterized by an average annual temperature of $9.2^{\circ} \mathrm{C}$, $828 \mathrm{~mm}$ annual precipitation and well-draining, and shallow sandy soils rich in organic matter suitable for root crop trials. Puch is characterized by an average annual temperature of $8.8^{\circ} \mathrm{C}, 913 \mathrm{~mm}$ annual precipitation, and heavy clay loam soils. The objectives of the numerous field experiments were to

- identify the most suitable accession or cultivar;

- compare crop establishment by direct seeding as opposed to planting out transplants at different plant densities;

- compare cultivation on flat soil as opposed to cultivation in ridges (mainly root crops);

- quantify the effect of different $\mathrm{N}$ fertilization rates (for Astragalus only) or $\mathrm{N}$ formulation (stabilized ammonia, for Artemisia only),

- compare methods of shading (for Angelica sinensis only);

- quantify the effect of flower removal (for Astragalus and Paeonia only);

- identify the required cultivation time, i.e. root harvest after one or more years of cultivation;

- compare harvesting frequencies and dates for above-ground material;

- optimize harvest and post-harvest methods for fruits, spikes, or roots.

All treatments were evaluated for their crop development, yield, and pharmaceutical quality of the dried plant material. The concentration of nutrients in the above-ground material for all species and additionally in roots for root crops was determined so as to establish fertilization recommendations.

It would exceed the scope of this paper to present the results in detail. However, some key information will be given for each plant species for which production methods are available. The BLBP number refers to the accession released to farmers.

Angelica dahurica: BLBP 02, seed soaking, stratification or germination at fluctuating temperatures, sowing in autumn $\left(1 \mathrm{~kg} \cdot \mathrm{ha}^{-1}\right)$ or planting out in spring (3-5 plants per stand, 50-80000 stands $\mathrm{ha}^{-1}$ ), harvest in autumn after one growing season, $15-20 \mathrm{t} \cdot \mathrm{ha}^{-1}$ fresh, 3.7-5.2 $\mathrm{t} \cdot \mathrm{ha}^{-1}$ dried root yield.

Artemisia scoparia: BLBP 01, soil with low cadmium availability, planting out in spring, 3-5 plants per stand, about 80000 stands $\mathrm{ha}^{-1}, 2$ to 6 harvests depending on plant height at harvest, 10$20 \mathrm{t} \cdot \mathrm{ha}^{-1}$ fresh, $2-5 \mathrm{t} \cdot \mathrm{ha}^{-1}$ dried total herb yield, remove stems after drying; one-year crop.

Astragalus mongholicus: BLBP 04, seeds with hard seed coat, seed treatment possible, sowing $\left(1.5 \mathrm{~kg} \cdot \mathrm{ha}^{-1}\right.$, treated $)$ or planting out in spring ( 1 plant per stand, about 80000 stands ha ${ }^{-1}$ ), remove inflorescences at flowering, harvest in autumn after one growing season, 3-5 t $\cdot \mathrm{ha}^{-1}$ fresh, $1.3-2.4 \mathrm{t} \cdot \mathrm{ha}^{-1}$ dried root yield.

Leonurus japonicus: BLBP 02, planting out in spring, 2-4 plants per stand, one harvest, $20 \mathrm{~cm}$ minimum cutting height, 18$22 \mathrm{t} \cdot \mathrm{ha}^{-1}$ fresh, 3.6-4.4 $\cdot \mathrm{ha}^{-1}$ dried herb yield; one-year crop.

Prunella vulgaris: BLBP 01 , sowing $\left(1 \mathrm{~kg} \cdot \mathrm{ha}^{-1}\right)$ or, more reliable, planting out in spring (2-4 plants per stand, 53-80000 stands $\mathrm{ha}^{-1}$ ), harvest of short shoots of $15 \mathrm{~cm}$ maximum length just after 
flowering, rapid drying, 3-10 $\cdot \mathrm{ha}^{-1} \cdot \mathrm{a}^{-1}$ fresh, $1-3 \mathrm{t} \cdot \mathrm{ha}^{-1} \cdot \mathrm{a}^{-1}$ dried short shoots, measures to improve microbiological quality may be necessary; two-year crop.

Salvia miltiorrhiza: BLBP 01 , sowing $\left(0.8 \mathrm{~kg} \cdot \mathrm{ha}^{-1}\right)$ or planting out in spring (1 plant per stand, about 80000 stands ha ${ }^{-1}$ ), harvest in autumn of the same or second year, second year harvest with higher yield but lower level of tanshinone II a, 5-20 t $\cdot$ ha $^{-1}$ fresh, $2-6 \mathrm{t} \cdot \mathrm{ha}^{-1}$ dried root yield, remove fine rootlets.

Saposhnikovia divaricata: BLBP 03, seed soaking or stratification, sowing $\left(2 \mathrm{~kg} \cdot \mathrm{ha}^{-1}\right)$ or planting out in spring (1 plant per stand, about 80000 stands ha $\left.{ }^{-1}\right), 8-12 \mathrm{t} \cdot \mathrm{ha}^{-1}$ fresh, $2.3-3.5 \mathrm{t} \cdot \mathrm{ha}^{-1}$ dried root yield, remove fine rootlets.

Scutellaria baicalensis: BLBP 02, sowing $\left(1.5 \mathrm{~kg} \cdot \mathrm{ha}^{-1}\right)$ or planting out in spring ( 1 plant per stand, about 80000 stands ha $^{-1}$ ), harvest in autumn of same year, if plant roots are thin, a second year will be beneficial, $0.5-2 \mathrm{t} \cdot \mathrm{ha}^{-1}$ fresh, $0.2-1 \mathrm{t} \cdot \mathrm{ha}^{-1}$ dried root yield, remove fine rootlets.

Sigesbeckia pubescens: BLBP 01, soil with low cadmium availability, sowing, $1 \mathrm{~kg} \cdot \mathrm{ha}^{-1}$, one harvest at beginning of flowering, cutting level above yellow leaves and very thick stems, 20$90 \mathrm{t} \cdot \mathrm{ha}^{-1}$ fresh, $4-13 \mathrm{t} \cdot \mathrm{ha}^{-1}$ dried herb yield depending on cutting level $(70-20 \mathrm{~cm})$.

Xanthium sibiricum: BLBP 01, deep sowing in spring, $30 \mathrm{~kg} \cdot \mathrm{ha}^{-1}$, threshing when most fruits are brown, 1.6-4.5 dried fruit yield, remove spikes, measures to improve microbiological quality may be necessary.

Results of other species which have not yet been released for farmers' practice are as follows:

For Rheum palmatum/R. officinale a production method was developed leading to a high yield and anthraquinone level in roots. However, the dry root materials mostly contained traces of rhaponticin despite their proven botanical identity. Therefore, Rheum cannot yet be recommended for commercial production unless the pharmacopoeia describes a critical maximum level for rhaponticin instead of qualitative absence via TLC.

Research for the production of Paeonia lactiflora (Paeoniae radix rubra) and Bupleurum chinense is still going on. For paeony, two standard cultivars used for ornamental purposes showed a high potential in root yield and paeoniflorin level. The root yield of $\mathrm{Bu}$ pleurum harvested after one year of cultivation is too low to make production economical. In addition, the number of plants surviving the winter to grow a second season for thicker roots is too small. Therefore, Bupleurum has not yet been released to the farmers, and a breeding program is underway to obtain more vigorous and robust plants. Field experiments and seed adaptation of Coix lacryma-jobi and Glycyrrhiza uralensis have just been started.

In the case of some species, the field experiments showed that they could not be cultivated under south German conditions. The plants of Angelica sinensis could not stand the high summer temperatures of the lowlands while vigorous plant development was observed in a small plot in northern Italy at a height of $1300 \mathrm{~m}$. The creeping plants of Tribulus terrestris established very well. However, the harvesting technology and yield potential was critical for this plant. One clone of Ligusticum chuanxiong that could be obtained is still being propagated. Since shading is needed, it was suggested that it be tested under more alpine conditions like Angelica sinensis.

\section{Breeding program}

The first step towards adapting the seed accessions to the local growing conditions as mentioned above was realized by positive mass selection of populations. However, for some species, the typical characteristics of wild plant species such as high variability could not be reduced satisfactorily. In addition, agricultural measures alone were not sufficient to ensure that plants could be produced economically or that all quality criteria could be fulfilled. Therefore breeding work was started in 2004 with Artemisia scoparia, Astragalus mongholicus, Bupleurum chinense, and Leonurus japonicus. Salvia miltiorrhiza and Saposhnikovia divaricata followed in 2007 and 2008, respectively. The selection criteria and breeding methods for each species are described in $\bullet$ Table 2.

Large genetic variability as well as knowledge on flowering and fertilization characteristics are prerequisites for successful crop improvement. Therefore further accessions were obtained from seed banks or other new sources. Due to the lack of specific literature for these species, experiments to understand flower initiation and mode of fertilization were conducted. In addition, methods for vegetative propagation in the greenhouse or via tissue culture had to be developed to create clones from selected individuals.

Artemisia scoparia was identified as a fully cross-fertilizing species based on a genetic marker study of two parents and $\mathrm{F}_{1}$-progenies after random mating (open pollination). This has been verified by clone isolation which revealed self-incompatibility for this clone. The conditions for floral induction varied among the accessions. The critical hours of daylight which must not be exceeded were 12 and about 16 hours for the respective accession. The plants of the accession requiring less than 12 hours of daylight do not flower before late autumn and, hence, do not reproduce under south German conditions. Artificial darkening is therefore required to prepare these plants for crossing programs. Artemisia can easily be propagated by cuttings in the greenhouse. Clones of 25 selected individuals were produced, cross-pollinated in a polycross design and tested for their general combining ability. Clones with high combining ability regarding high yield and a low level of cadmium were selected and will be combined for a synthetic cultivar.

Astragalus mongholicus was identified as a cross-fertilizing species which requires insects for pollination. All accessions flowered easily and produced seed. A tissue culture method using nodal segments was developed for Astragalus with varying multiplication rates depending on the clones.

A total of 200 Astragalus individuals were selected and propagated via tissue culture in 2004 to 2006 . Twenty-four clones were tested for their combining ability after random mating in a polycross. The progenies of three clones were exceptional with respect to their yield and root thickness together with high astragaloside IV and good extractives content levels. In another field trial comparing another 67 clones, further superior clones were identified which will now be randomly mated in a polycross design for subsequent combining ability studies.

Likewise, Leonurus japonicus is mainly cross-pollinating and intensively visited by bees and bumble bees during flowering. Self-fertilization was observed under isolation conditions. For breeding purposes, only accessions flowering during the first cropping season were chosen for individual selection. Twentyfour Leonurus individuals were selected and propagated using tissue culture methods which were developed. Propagation through nodal segments was practical. However, bacterial infestations were a continual challenge. In $F_{1}$-progenies of several 
Table 2 Selection criteria and breeding method of selected species.

\begin{tabular}{lll}
\hline $\begin{array}{l}\text { Plant species } \\
\text { Artemisia scoparia }\end{array}$ & $\begin{array}{l}\text { Selection criteria } \\
\text { low level of cadmium, high yield, homogeneity } \\
\text { high yield for one-year cropping, thick roots, high level of astragaloside IV mongholicus } \\
\text { and extractives }\end{array}$ & $\begin{array}{l}\text { Breeding method/cultivar type } \\
\text { clone selection/synthetic } \\
\text { clone selection/synthetic }\end{array}$ \\
$\begin{array}{ll}\text { Bupleurum chinense } \\
\text { Leonurus japonicus }\end{array}$ & $\begin{array}{l}\text { vitality and hardiness for two-year cultivation and higher yield } \\
\text { homogenous start of flowering, high yield, hardiness for second year } \\
\text { cropping }\end{array}$ & $\begin{array}{l}\text { individual selection, testing of } \mathrm{S}_{1} \text {-progenies/population } \\
\text { clone selection/synthetic }\end{array}$ \\
\hline Salvia miltiorrhiza & $\begin{array}{l}\text { disease tolerance, high yield, homogenous start of flowering, } \\
\text { low proportion of fine rootlets }\end{array}$ & clone selection/synthetic \\
\hline Saposhnikovia divaricata & $\begin{array}{l}\text { hardiness, high vernalization and shooting rate, high seed germination } \\
\text { rate and speed }\end{array}$ & individual selection, testing of $\mathrm{F}_{1-\text {-progenies/population }}$
\end{tabular}

clones, flowering was later and more homogenous compared to their original populations resulting in a higher yield. The proportion of plants growing for a second season was slightly higher in some progenies, but resulting ground coverage was much too small. Therefore the breeding aim of second-year cropping was dropped.

Salvia miltiorrhiza was concluded to be cross-fertilizing due to low seed-setting after isolation of inflorescences. Seeds from self-fertilization were viable. The frequently observed leaf spots, wilting, or senescence of flowering shoots could not be attributed to a specific fungi, bacteria or virus. In contrast, ubiquitary fungi and bacteria were isolated from affected plants. It was concluded that secondary infestation along with ripening of the plant after flowering caused the symptoms. Clones of 28 selected individuals were established by top and node cuttings in the greenhouse. Several high yielding and healthy clones were identified in field tests at two locations.

Bupleurum chinense and Saposhnikovia divaricata, both representatives of the Apiaceae family, are cross-fertilizing species. Self-mating of individual plants was achieved by releasing flies inside the isolation cover to overcome self-incompatibility mechanisms. Bupleurum develops flowers and seed in the first, and Saposhnikovia in the second season. Since no vegetative propagation method for Bupleurum was available initially, $\mathrm{F}_{1}$ - and subsequently $\mathrm{S}_{1}$-progenies were generated from selected individuals for field evaluation. Assuming the same behavior for Saposhnikovia, the same breeding method for population improvement was chosen.

Pharmaceutical quality: comparison of experimental materials to those imported from Asia

Selected samples of ten species from experimental cultivation harvested in 2003 to 2005 and from commercial import bought anonymously from different wholesalers via two pharmacies in 2004-2006 were compared. The species were Angelica dahurica, Artemisia scoparia, Astragalus mongholicus, Bupleurum chinense, Leonurus japonicus, Prunella vulgaris, Salvia miltiorrhiza, Saposhnikovia divaricata, Scutellaria baicalensis and Sigesbeckia pubescens. Ten experimental and imported samples per species, respectively, were analyzed for their pharmaceutical quality, i.e., identity, purity, and level of active ingredients in accordance with the Chinese and European pharmacopoeia [6-8], as well as for their sensory quality.

The results were published in detail $[10,11]$. It is difficult to make general conclusions about the quality of both imported and experimental herbal drugs. The quality of the imported samples was highly variable. They differed in their appearance, purity and level of active ingredients. Only 77 out of 100 imported samples met the official requirements of the pharmacopoeias. Problematic criteria included levels of microbiological, heavy metal or pesticide contamination that were too high. In single cases, the plant species the herbal drug was derived from did not comply with the pharmacopoeia, or the level of active ingredients or extracts was too low. It is noteworthy that the materials of two out of eleven wholesalers completely complied with the quality standards. The quality of the experimental material was also variable. The variation could mostly be explained by experimental treatments, mainly accession and harvest parameters. Single critical qualities that emerged during the study (e.g., cadmium accumulation of Artemisia and Sigesbeckia) were translated into recommendations for farmers' practice in order to ensure high product quality. The taste of decoctions from experimental and imported herbal drugs complied with the sensory descriptions of the Chinese pharmacopoeia [6,7] in most cases. Almost all imported samples of Salvia miltiorrhiza, Prunella vulgaris, and Sigesbeckia pubescens as well as single samples of other species produced an unpleasant mouldy off-taste. This hints at decay of the sample material which may be a result of inappropriate post-harvest practices like drying it too slowly, incomplete drying, exposing the product to sustained moisture before cutting, or incorrect transport or storage conditions. The experimental samples were characterized by their fresh aroma.

\section{Transfer to farmers}

In 2005, after six years of experimentation, a critical mass of statistically evaluated results as well as experiences on how to economically produce herbal drugs was gathered for the following plants: Angelica dahurica, Artemisia scoparia, Leonurus japonicus, Salvia miltiorrhiza, Saposhnikovia divaricata, Scutellaria baicalensis, and Sigesbeckia pubescens. At the same time, at least one accession per species with good agronomic and pharmaceutical qualities adapted to local conditions was identified, and larger seed quantities were made available by local farmers which multiplied the seed. Based on this, professional production of herbal drugs for CHM commenced for the first time in Germany in 2005 (see Figs. 1-3). Two herbal wholesalers commissioned three farmers in Franconia to cultivate these seven species. The farmers were experienced specialists who professionally cultivate and process European herbs such as Echinacea, St. John's wort, or lemon balm on a large scale. The production was supported by intensive consultation by U. Bomme and colleagues. Subsequently, Astragalus mongholicus could be started with, and more farmers and wholesalers joined the business. The cultivation area 


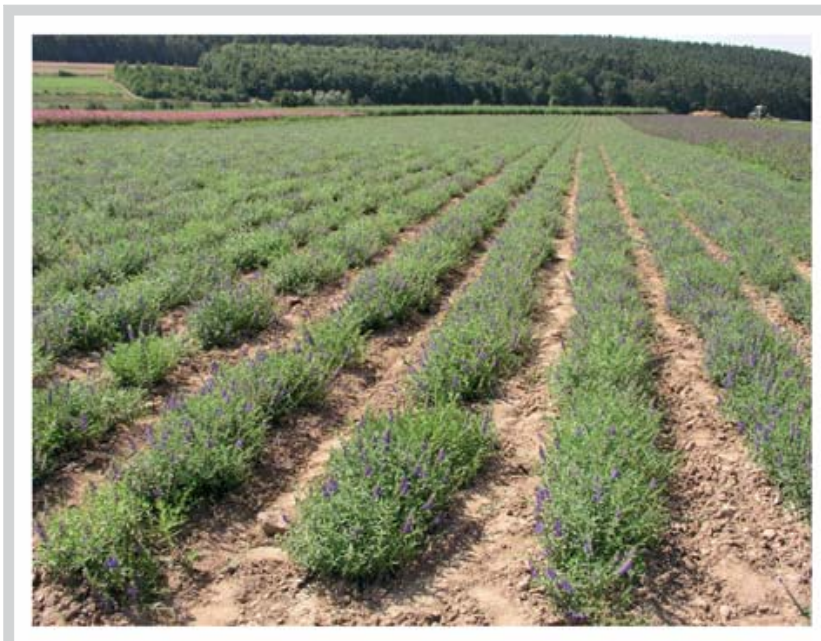

Fig. 1 Commercial field cultivation of Scutellaria baicalensis in Franconia. Author: U. Bomme, LfL.

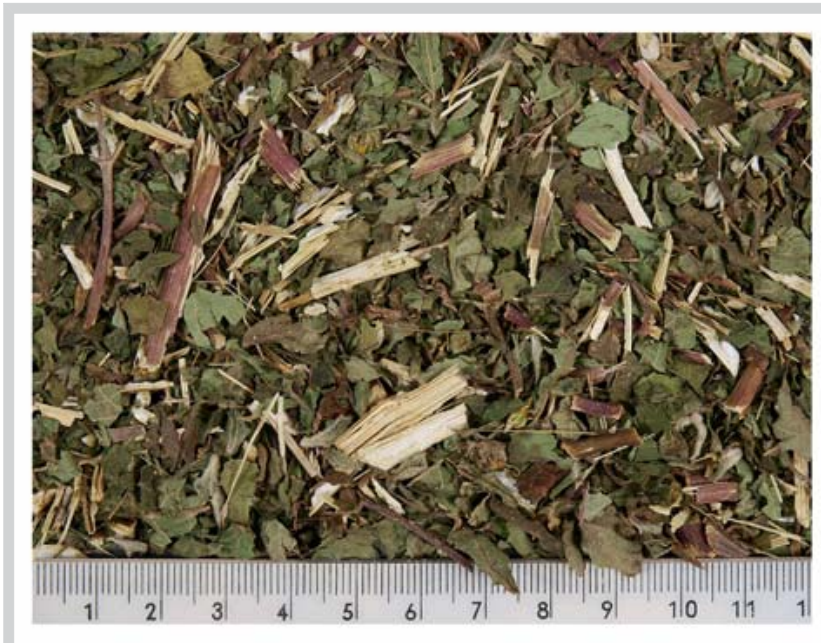

Fig. 3 Herba Sigesbeckiae, Xixiancao, produced in Franconia. Author: W. Seemann, LfL.

was 3 ha in 2005 and ranged between 3 and 5 ha in subsequent years.

At the same time, a number of activities were undertaken to inform users at various levels of the availability of locally produced herbal drugs for CHM and the advantages of the their documented and controlled production. This included publications in scientific and applied journals [12-15], presentations to farmers, wholesalers, pharmacists, physicians and industrial companies, as well as two workshops in Freising and Graz gathering all users for discussion [16]. Specimens of the field-cultivated herbal drugs were distributed on these occasions and posted to wholesalers and pharmacists by the farmer in charge of sales.

The experimental results and experiences were summarized in production manuals for farmers covering all aspects of cultivation and post-harvest treatments (not: pao zhi). Manuals were published for: Angelica dahurica, Leonurus japonicus, Prunella vulgaris, Rheum officinale, Salvia miltiorrhiza, Saposhnikovia divaricata, Scutellaria baicalensis, and Sigesbeckia pubescens [17].

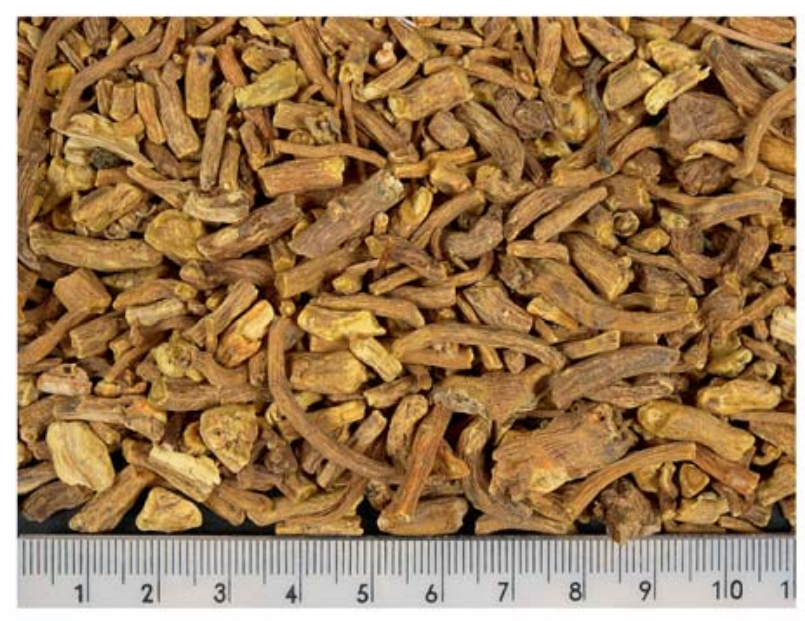

Fig. 2 Radix Scutellariae, Huangqin, produced in Franconia. Author: W. Seemann, LfL.

Manuals for Astragalus mongholicus, Artemisia scoparia, and Xanthium sibiricum are to follow soon. For all these species, the most suitable seed accession was placed in the hands of a seed trade company for seed multiplication and sale.

Meanwhile, the field cultivation has changed from pilot character to fully commercial herbal drug production. Large-scale production covering several hectares per species can be realized should demand merit it.

\section{Medicinal application}

The herbal materials from experimental production and, subsequently, commercial production in Franconia have been applied in medicinal practice by physicians of the associations DECA and SMS. As a result of the positive course of clinical applications that has been observed and the high pharmaceutical quality of the herbal materials, the therapeutic use of locally produced CHM herbs has been recommended [18].

\section{Conclusions}

$\nabla$

Applying the production recommendations and using the BLBPaccessions released by LfL, herbal drugs produced under German field conditions will have the correct identity and are presumed consistently to meet high standards with regard to the level of active ingredients and extractives that is required, with regard to the level of ash, microbiological and heavy metal contamination, as well as sensory attributes. This is ensured by specialized farmers applying high standards of hygiene and quality during cultivation, harvest, and post-harvest processing, as well as the restrictive European legislation for pesticide use and for maximum contamination levels of pesticide residues, heavy metals, and germs. Due to climatic and production conditions, the local production of CHM herbs will remain restricted to selected plant species in Germany. However, this approach to develop sustainable production methods for new species and their introduction to farmers' practice can be taken as a model to establish field production of more herbal materials used in CHM in Europe, China, and elsewhere. This is a step forward to improve herbal drug quality and safety, hence, to make it more reliable for all users. 


\section{Dedication}

$\nabla$

This paper is dedicated to Prof. Dr. Ulrich Bomme, LfL, who successfully led this comprehensive and sophisticated interdisciplinary project to the stage described in this paper. His strategic approaches, his ability to bring together and coordinate the project partners, as well as his consistent time and information management were essential to efficiently introduce a whole group of plant species used in CHM to farmers' fields and from there to the patients' decoctions. Finally, he has taken all precautions to ensure that this project of applied research will be continued after his retirement.

\section{Acknowledgements \\ $\nabla$}

Due to the nature of this interdisciplinary research, numerous persons, working groups, and institutions (see description of approach and project partners) contributed to its success, and their efforts are highly appreciated. However, they cannot be named and acknowledged individually at this point. Thanks are due to the Bavarian State Ministry of Nutrition, Agriculture and Forestry, the Agency of Renewable Resources (FNR, FKZ 22007703 and FKZ 22019707), and the companies PhytoLab, Kräuter Mix and Saatzucht Steinach for their financial support.

\section{Affiliations}

${ }^{1}$ Institute for Crop Science and Plant Breeding, Bavarian State Research Center for Agriculture (Lf), Freising, Germany

2 Institute of Pharmaceutical Sciences, Karl-Franzens-Universität Graz, Graz, Austria

${ }^{3}$ Klinik Silima, Gut Spreng, Riedering, Germany

${ }^{4}$ Institute of Systematic Botany, Ludwigs-Maximilians-Universität München, Munich, Germany

${ }^{5}$ SMS - International Society for Chinese Medicine, Munich, Germany

${ }^{6}$ Kräuter Mix GmbH, Abtswind, Germany

\section{References}

1 Ye K-Y. The illustrated Chinese material medica, crude and prepared. Taipei: SMC Publishing Inc.; 1992

2 Bensky D, Clavey S, Stoeger E, Gamble A, Bensky LL. Chinese herbal medicine: Materia medica, 3rd edition. Vista: Eastland Press; 2004

3 Hempen $\mathrm{C}-\mathrm{H}$, Fischer T. Guideline to Chinese herbal medicine (in German), 2nd edition. München: Urban und Fischer; 2007

4 Anonymous. Chinese herbs - cases of death in Belgium (in German). Dtsch Apoth Ztg 2000; 140: 115-116

5 Schmoltzi P, Scherges M. Mix-ups of Chinese herbs (in German). Dtsch Apoth Ztg 2000; 140: 4094-4103

6 Pharmacopoeia of the People's Republic of China, English edition, Vol. 1. Beijing: Chemical Industry Press; 2000

7 Pharmacopoeia of the People's Republic of China, English edition, Vol. 1. Beijing: People's Medical Publishing House; 2005

8 European Pharmacopoeia, 4th and 5th Volume. Eschborn: Govi-Verlag; 2002/2005

9 Bomme U, Gatterer M. Methods of germination improvement of medicinal and spice plants and their use on a few Chinese medicinal plants (in German, English abstract). Z Arzn Gewpfl 2002; 7 (special edition): 133-148

10 Heuberger H, Bomme U, Friedmann B, Groß J, Kabelitz L, Reif K, Schmücker $R$, Torres-Londono P. Quality of herbal raw materials for traditional Chinese medicine from Bavarian experimental cultivation compared to imported materials: identity, sensory quality, active principle content, purity (in German, English abstract). Chin Med 2008; 23: 119-135

11 Heuberger H, Bomme U, GroßJ, Kabelitz L, Reif K, Schmücker R. Constituent and extractives contents of selected herbal raw materials for traditional Chinese medicine from Bavarian experimental cultivation compared to imported materials from Asia (in German, English abstract). Z Arzn Gewpfl 2008; 13: 173-181

12 Friedl F, Bomme U. Chinese medicinal plants for our farmers? (in German) Z Arzn Gewpfl 1999; 4: 159-160

13 Bomme U. Cultivation of CHM plants (in German). Dtsch Apoth Ztg 2005; 145: 5604

14 Hummelsberger J, Bomme U, Friedl F. Chinese medicinal plants - German cultivation assures quality (in German). Dtsch Ärzteblatt 2006; 103: A1442-A1443

15 Bomme U, Bauer R, Friedl F, Heuberger H, Heubl G, Torres-Londono P, Hummelsberger J. Cultivating Chinese medicinal plants in Germany: A Pilot Project. J Altern Compl Med 2007; 13: 597-601

16 Bomme U. A chance for better drug quality in CHM - workshop on documented and controlled cultivation of selected species for CHM (in German). Z Phytotherapie 2008; 29: 194-196

17 Bomme U. Production manuals for plants used in the Chinese herbal medicine. http://www.lfl.bayern.de/ipz/heilpflanzen/16925/index. php. Accessed October 6, 2010

18 Nögel R. Quality of Chinese herbal drugs from Bavarian experimental cultivation compared to imported materials (in German). Chin Med 2008; 23: 107 